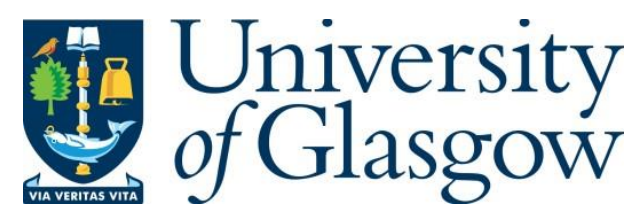

Evers, A. T., Yamkovenko, B. and Van Amersfoort, D. (2017) How to keep teachers healthy and growing: the influence of job demands and resources. European Journal of Training and Development, 41(8), pp. 670-686.

There may be differences between this version and the published version. You are advised to consult the publisher's version if you wish to cite from it.

http://eprints.gla.ac.uk/149709/

Deposited on: 8 January 2018

Enlighten - Research publications by members of the University of Glasgow http://eprints.gla.ac.uk 


\title{
Title: How to Keep Teachers Healthy and Growing: The Influence of Job Demands and Resources ${ }^{1}$
}

\author{
Arnoud T. Evers \\ Open University of the Netherlands, Welten Institute, Research Centre for Learning, \\ Teaching and Technology \\ arnoud.evers@ou.nl
}

\section{Bogdan Yamkovenko}

Towson University, Maryland, USA, Department of Psychology byamko1@gmail.com

\section{Daniël Van Amersfoort}

Open University of the Netherlands, Welten Institute, Research Centre for Learning, Teaching and Technology daniel.vanamersfoort@ou.nl Future correspondence (corresponding author):

\author{
Arnoud T. Evers \\ Open University of the Netherlands \\ Valkenburgerweg 177 \\ 6401 DL Heerlen \\ Telephone number: +31-(0)6-21112457 \\ Fax number: +31-(0)45-5762782 \\ E-mail address: arnoud.evers@ou.nl
}

\footnotetext{
${ }^{1}$ See for the article as published online: DOI: doi.org/10.1108/EJTD-03-2017-0018. Please refer to this article as: Evers, A. T., Yamkovenko, B., \& Van Amersfoort, D. (2017). How to Keep Teachers Healthy and Growing: The Influence of Job Demands and Resources. European Journal of Training and Development, 41(8), 670-686.
} 


\begin{abstract}
Purpose

Education depends on high-quality teachers who are committed to professional development and don't get burned out. The purpose of this paper was to investigate how job demands and resources can affect the health and cognitive development of teachers using the Demand-Induced Strain Compensation model (DISC).
\end{abstract}

\title{
Design/methodology/approach
}

A cross-sectional sample of 120 teachers in vocational education was used to investigate the proposed relationships and hypotheses with Ordinary Least Squares (OLS) regression method.

\section{Findings}

In terms of teacher health and development, significant main effects were found for several predictors. Autonomy was significantly and negatively related to emotional exhaustion. Autonomy, emotional supervisor and colleague support were significantly and positively related to teachers' development. However, little support was found for matching hypotheses, suggesting that matching demands and resources do not offer more explanatory power for occupation outcomes than other types of interaction effects.

\section{Research limitations}

More powerful analyses techniques like structural equation modeling could be used in future research with a larger sample size. A second limitation is common method variance.

\section{Practical implications}

Schools in vocational education should provide sufficient job resources, such as autonomy and emotional support, but possibly also put a limit on teacher task variety.

\section{Originality/value}

Job demands and resources have until now mainly been related to negative outcomes such as poor health and ill-being, while the relationship with learning has also been hypothesized and is therefore meaningful to examine. In addition, it was investigated whether interaction effects of matching demands and resources, better explain these outcomes.

Keywords: health outcomes; cognitive occupational outcomes; demand-induced strain compensation model; continued education 


\section{Introduction}

Nowadays two topics seem to dominate the literature and political debate on teachers: health related issues and continued education. High turnover intentions among teachers have brought attention to health issues, especially emotional exhaustion (Carson et al., 2010). Continued education for teachers has received a lot of attention since policy makers and researchers have noted that good education requires good teachers (Hattie, 2008). Particular interest has been given to professional development in the workplace (Avalos, 2011; Evers et al., 2011b) and the development of other cognitive occupational outcomes like occupational expertise and personal flexibility (Evers et al., 2016). For emotional exhaustion, the main question is how it can be prevented. In contrast, the question for continued professional development, occupational expertise and personal flexibility is: how can we stimulate it?

The Demand-Induced Strain Compensation (DISC) model, can help address both these questions. In this model the role of job demands and job resources in relation to several outcomes is investigated. Until now, occupational health research has still mainly been focused on negative outcomes such as poor health and ill-being (Van den Tooren and De Jonge, 2008; Van der Heijden et al., 2008). Given the association between job demands and resources and active learning and growth (Bakker and Demerouti, 2007), it is worthwhile to investigate the association with continued professional development, occupational expertise and personal flexibility as well.

Researchers have hypothesized interaction effects of job demands and job resources (Bakker and Demerouti, 2007; Evers et al., 2011a). In studying these interaction effects it is recommended to study specific matching job demands and job resources, as explained, amongst others, in Van den Tooren and De Jonge (2008). 
In this study we therefore investigate the relationship between job demands, job resources, along with their matching interaction effects on the one hand, and health and cognitive occupational outcomes of teachers in vocational education (that is continued professional development, occupational expertise and personal flexibility) on the other.

\section{Theoretical background}

\section{DISC model}

Job demands are defined as the degree to which the work environment has stimuli that need different kinds of sustained physiological and psychological effort (Jones and Fletcher, 1996). Van den Tooren and De Jonge (2008) explain how nurses need to deal with dying patients and suffering on a frequent basis, which causes emotional exhaustion and burnout (Misiołek et al., 2017). Eventually, job demands for teachers may also lead to negative health outcomes such as emotional exhaustion and overall burnout (Nie and Sun, 2015; Pu et al., 2016; Webb and Napier, 2015).

Job resources can compensate for negative effects of job demands. They can be defined as energetic reservoirs in the work environment. There are several types of job demands and job resources. These are cognitive, emotional, and for some professions also physical, job demands and resources (Van den Tooren and De Jonge, 2008). For instance, Bernabé and Botia (2015) found that emotional social support was negatively correlated to fire-fighters' emotional exhaustion, which might also be the case for teachers. Physical demands as a factor, are less relevant for our purposes (see also Evers et al., 2011a), as the work of teachers does not include physical labor, like, for instance, those in the nursing or fire-fighters' profession.

Besides health related issues, job demands and job resources are hypothesized to be associated with active learning and growth as well (Bakker and Demerouti, 2007). 
Active learning and growth are assumed to be stimulated when "arousal", caused by job demands, is changed into a direct (learning) action by application of job resources (De Jonge and Dormann, 2003). A particular learning action for teachers, receiving more attention nowadays, is teachers' professional development (TPD) at work as it is supposed to be more effective for learning than traditional training courses (Evers et al., 2011b). Apart from TPD, occupational expertise and personal flexibility are also essential for teachers' learning and growth. Teachers need to be experts in their occupation, and at the same time need to be able to cope with change (Evers et al., 2016). Occupational expertise consists of knowledge, meta-cognitive knowledge, skills and social recognition (Van der Heijde and Van der Heijden, 2006). Personal flexibility is defined as the capacity for smooth transitions between jobs and between organisations as well as adapting easily to all kinds of changes in the internal and external labour market (Van der Heijde and Van der Heijden, 2006). To conclude, in this article, besides health problems, we will also focus on TPD at Work, occupational expertise and personal flexibility.

Job demands and resources are regarded as generic concepts that can be universally applied (Bakker and Demerouti, 2007). However, making no distinction between different types of demands and resources (like for teachers emotional and cognitive), might also obscure the differential effects of specific matching components. De Jonge et al. (2008) in their DISC model proposed three types of matches between job demands, job resources and relevant outcomes.

The first match is called the double match of common kind:

$$
\text { Demand type }=\text { Resource type } \neq \text { Outcome type }
$$

This match occurs when cognitive demands are compensated by cognitive resources, or 
when emotional demands are overcome using emotional resources (De Jonge and Dormann, 2003; De Jonge and Dormann, 2006; Van den Tooren and De Jonge, 2008). For instance, cognitively challenging work tasks are most easily compensated for by job autonomy, while emotionally distressful work is more likely to be compensated by emotional colleague support.

If, for some reason, matching resources do not suffice or are simply not available, employees will search for other, less matching, job resources. They may even use resources that do not match their job demands, which we call 'lower order' matches (De Jonge and Dormann, 2006). This is the idea of double match of extended kind (Frese, 1999):

$$
\begin{aligned}
& \text { Resource type } \neq \text { Demand type }=\text { Outcome type } \\
& \text { Demand type } \neq \text { Resource type }=\text { Outcome type }
\end{aligned}
$$

The first expression shows that demand and resource types do not match, but the demand type does match the outcome type. For example, an employee may leverage their job autonomy to compensate for their emotionally distressful work to limit their emotional exhaustion. The second formula shows that a double match of the extended kind may occur when the resource type matches the outcome type, but where demands are of a different type. An example for this is an employee who uses their emotional colleague support to compensate for high task variety (a cognitive demand) to reduce their emotional exhaustion.

The last possible combination is the one where the outcomes match both job demands and job resources:

Demand type $=$ resource type $=$ outcome type 
This is called triple match (De Jonge and Dormann, 2003). This is the case when cognitive demands match with cognitive resources, and cognitive outcomes, or when emotional demands match with emotional resources, and emotional outcomes. In case of triple match, job resources are likely to moderate the relationship between high job demands and job related outcomes (Van den Tooren and De Jonge, 2008). When demands, resources and outcomes are all different, moderating effects are least likely to take place; then we speak of non-match.

Drawing on the discussion above, we formulated the following hypotheses. With regard to the direct additive effects of job demands: Hypothesis 1: Job demands are positively associated with emotional exhaustion.

With regard to the direct or additive effects of job resources: Hypotheses 2a: Job resources are negatively associated with emotional exhaustion. Hypothesis 2b: Job resources are positively associated with teachers' professional development (TPD) at work.

Hypothesis 2c: Job resources are positively associated with occupational expertise. Hypothesis 2d: Job resources are positively associated with personal flexibility.

With regard to interaction effects of job demands and job resources, in accordance with Van den Tooren and De Jonge (2008), we formulated the following propositions of relationships. First of all the double match of common kind: Hypothesis 3: There is a match between demand and resource type (emotional or cognitive), but not the outcome type.

With regard to the double match of extended kind: 
Hypothesis 4: Demand and resource type (emotional or cognitive) do not match, but demand or resource type match the outcome type.

The hypothesis belonging to the triple match:

Hypothesis 5: Demand type match the resource type (emotional or cognitive) and outcome type.

\section{Method}

\section{Sample and procedure}

An anonymous survey was administered to teachers in one school for vocational education in the Netherlands. The survey was pilot tested with several teachers and school leaders of this school. An e-mail was sent with a unique link to the digital survey (with two reminders) to all teachers in the school (convenience sample). The data was collected during a period of half a year; it took some time to reach all the departments in the school. Of the 120 respondents (response rate $8 \%$ ), $60 \%$ were male. The majority $(82 \%)$ completed an applied university, $11 \%$ completed a 4-year university, and $7 \%$ had vocational training. One person completed high school. On average, the respondents had 18.61 years of experience in teaching. Males had 17.57 years of experience; females had 20.17 years of experience.

\section{Measures}

Emotional exhaustion: "a feeling of being emotionally worn out and having reached the end of one's rope" (Van den Tooren and De Jonge, 2008, p. 78). We used a three item scale based upon Van den Tooren and De Jonge (2008). An example of an item was: “Do you feel mentally exhausted because of your work?”. Cronbach's alpha was .85. 
TPD at Work is a 21-item measure with 6 subscales (Evers et al., 2016). Participants responded to each item using a four-point scale (ranging from $1=$ hardly ever, to $4=$ often). Teachers were asked how often they participated in each professional learning activity. The first subscale, keeping up to date: reading, consisted of three items. Cronbach's alpha was .79. An example item was: "Reading educational/subject matter pedagogical literature." The second subscale, keeping up-to-date: participation in training related to work, had two items. Cronbach's alpha comprised .75. An example item was: "Participating in a training course that centres around subject matter pedagogy." The third subscale, experimenting, consisted of five items. An example item was: "Inquiring new teaching methods in class." Cronbach's alpha was .87. Reflecting and asking for feedback, the fourth subscale, had four items. An example item was: "Reflecting on my strong and weak points.” Cronbach's alpha comprised .71. Three items were used for the fifth subscale, collaborating with colleagues with the aim of improving lessons. An example item was: "Preparing lessons with colleagues." Cronbach's alpha was .72. Finally, the sixth subscale, collaborating with colleagues with the aim of improving school development, was based on four items. An example item was: "Giving an opinion together with colleagues about school organisational matters to the school management." Cronbach's alpha comprised .73.

Occupational expertise and personal flexibility, were measured with 15 and 8 items respectively of the scales of Van der Heijde and Van der Heijden (2006). Items were scored using six-point rating scales (ranging from: $1=$ very poor, to $6=$ very good, for occupational expertise, and $1=$ a very great deal of difficulty, to $6=$ very little difficulty, for personal flexibility). An example item of occupational expertise was: "I consider myself competent to engage in in-depth, specialist discussions in my job domain". Cronbach's alpha .85. An example item of personal flexibility was: "How 
easily would you say you can adapt to changes in your workplace?" Cronbach's alpha .79 .

Cognitive job demands: "primarily impinge on the brain processes involved in information processing" (Van den Tooren and De Jonge 2008, p. 76). This scale comprised four items, scored on a four-point rating scale ranging from $1=$ hardly ever, to $4=$ always. It was based upon Van den Tooren and De Jonge (2008) and Hockey (2000). An example item was: "Do you need to take difficult decisions in your work?". Cronbach's alpha 67.

Cognitive job demands: Task variety: 'the availability of learning opportunities as well as the amount of diversity the work offers' (Kwakman 2001, p. 490). Although task variety is seen as job enrichment (Hackman and Oldham, 1980), it is also seen as a job demand (Kwakman, 2003). The scale originally originated from Van Veldhoven and Meijman (1994) and comprised four items. Items were scored using a four-point rating scale ranging from $1=$ hardly ever, to $4=$ always. An example item was: 'Is your work diverse?' Cronbach's alpha .78.

Emotional job demands: 'the effort needed to deal with job inherent emotions and/or organizationally desired emotions.' (Van den Tooren and De Jonge 2008, p. 76). This scale was derived from Kwakman (2003), originally Van Veldhoven and Meijman (1994), and comprised four items. Items were scored using a four-point rating scale ranging from $1=$ hardly ever, to $4=$ always. An example item was: 'Is your work emotionally constraining?'. Cronbach's alpha .72.

Cognitive job resource: autonomy: 'the opportunity of the teacher to determine different task-related characteristics.' (Kwakman 2003, p. 161). This scale was derived from Kwakman (2003) and comprised five items. Items were scored using a four-point rating 
scale ranging from $1=$ hardly ever, to 4 = always. An example item was: 'Do you have influence on the planning of your work?' Cronbach's alpha .84 .

Emotional job resource: Emotional colleague support. This means colleagues providing sympathy and affection (Van den Tooren and De Jonge, 2008, p. 76). This scale was based upon Karasek et al. (1982) and De Jonge et al. (2006) and comprised four items. Items were scored using a four-point rating scale ranging from $1=$ hardly ever, to $4=$ always. An example item was: 'My closest colleagues are willing to listen to my workrelated problems.' Cronbach's alpha .92.

Emotional job resource: Emotional supervisor support. An important emotional job resource is a supervisor providing sympathy and affection (Van den Tooren and De Jonge 2008, p. 76). This scale was based upon Karasek et al. (1982) and De Jonge et al. (2006) and comprised four items. Items were scored using a four-point rating scale ranging from $1=$ hardly ever, to $4=$ always. An example item was: 'My immediate supervisor pays attention to what I say'. Cronbach's alpha .95 .

In addition we collected demographic data about the participants including gender, experience, and educational level.

\section{Data analysis}

Data were analysed using the OLS (Ordinary Least Squares) regression method. We did not detect any meaningful violations of linear regression assumptions. The demographic variables were entered first as control variables. They were not significant in any of the models and were excluded from the analyses. The variables for which interaction terms were computed were mean-centred prior to analysis to remove multicollinearity and to facilitate the interpretation of the interaction terms. To test the hypotheses we used the hierarchical regression approach. We first entered Job Resources only (autonomy, 
emotional supervisor support, and emotional colleague support), to predict job-related outcomes (emotional exhaustion, TPD at Work, occupational expertise and personal flexibility). We then entered interaction terms for Job Demands (task variety, cognitive demands and emotional demands) and Job Resources into the model for each jobrelated outcome. We then conducted extra-sums of squares tests for these models to determine whether interaction terms significantly contributed to the model. Extra-sums of squares test is a procedure used to investigate the contribution of a subset of predictors to the model (Montgomery et al., 2012).

For the TPD at Work outcome, given the moderate significant correlations among its scales, we used a multivariate regression approach, with all six scales entered as six dependent variables. This methodology is more effective than running six individual univariate regressions because multivariate approach allows to take into account the relationship between the dependent variables (Johnson and Wichern, 2002). For Hypotheses 3, 4 and 5, following De Jonge and Dormann (2006), we tested the matching interactions terms. To test the matching hypotheses we fit four regression models, one to each occupational or job outcome with the demands and resources, and their interactions as predictors.

\section{Results}

The means, standard deviations, correlations and reliability estimates are presented in Table 1. Significant correlations among the TPD at Work scales support the multivariate regression approach for hypotheses $2 \mathrm{~b}, 3,4$ and 5. Personal flexibility and occupational expertise were positively associated with the following job resources: cognitive autonomy $(r=.28, p<.001, r=.31, p<.01$ for personal flexibility and occupational expertise respectively), emotional supervisor support $(r=.27, p<.01, r=23, p<.01$ 
for personal flexibility and occupational expertise respectively) and emotional colleague support ( $r=.23, p<.01$ only for occupational expertise). Emotional exhaustion was negatively associated with emotional support from colleagues, $(r=-.18, p<.05)$ and cognitive resources $(r=-.31, p<.001$ for autonomy).

********** Insert Table 1 about here $* * * * * * * * * * * * * * *$

Multivariate tests (Type II Multivariate Analysis of Variance) of the model predicting TPD at Work with Job Resources showed a significant multivariate relationship between TPD at work and emotional colleague (Pillai Tr. .15, $p<.01$ ) and supervisor support (Pillai Tr. .13, $p<.05$ ). Pillai's trace was used as it is a robust statistic, which is generally considered to be more powerful than others (Olson, 1979). Emotional colleague and supervisor support predicted TPD at work, while autonomy did not.

Multivariate regression results for the associations of Job Resources with TPD at Work showed that emotional colleague support significantly predicted collaborating on lessons improvement $(B=.24, p<.05)$ and collaborating on school development $(B=$ $.25, p<.01)$. Emotional supervisor support significantly predicted all six TPD at Work scales (Reading, $B=.31, p<.001$; Training, $B=.21, p<.05$; Experimenting, $B=.22, p$ $<.01$; Reflecting, $B=.17, p<.01$; Collaborating on lessons improvement, $B=.15, p<$ .05 ; Collaborating on school development $B=.16, p<.05)$. Hypothesis $2 \mathrm{~b}$ is therefore partially supported.

Table 2 shows the results of the regression analysis for the direct additive effects of job demands and job resources (Hypotheses 1, 2a, 2c and 2d), double matches of common and extended kind, and triple matches. Emotional demands significantly predicted emotional exhaustion. Hypothesis 1 was therefore supported. Emotional demands also had a negative relationship with occupational expertise and personal 
flexibility. Of the three types of job resources, autonomy negatively predicted emotional exhaustion and positively occupational expertise. In addition, emotional colleague support was positively related to occupational expertise. Therefore, hypotheses $2 \mathrm{a}$ and 2c were partly supported. Job resources did not predict personal flexibility. Consequently, hypothesis $2 \mathrm{~d}$ was not supported.

With regard to hypotheses 3, 4 and 5 we started with testing TPD at Work as the outcome variable. The results of the multivariate regression for the TPD at Work variables indicated that none of the interactions were significant and therefore these are not shown in Table 2.

With regard to emotional exhaustion, occupational expertise and personal flexibility as the outcome variables, some interaction terms were significant as shown in Table 2. We used the abbreviation DMc for double match of common kind (job demands and resources match, but outcome does not). Triple match, where both job resources and job demands match the outcome, is identified as TP. For readability, we do not identify DMe for double match of extended kind (job demands or job resources match the outcome), because all remaining interaction terms in Table 2 fit this category. *********** Insert Table 2 about here $* * * * * * * * * * * * * * *$

The results indicated that only one interaction term was significant. This is a double match of an extended kind where cognitive demand (task variety) matches the cognitive job outcome (expertise), but the emotional resource (colleague support) does not match. Therefore, hypotheses 3 and 5 are not supported, while there is partial support for hypothesis 4 .

To test hypothesis 4 we fit both the reduced model (job resources and demands only) and a model with the interaction term of task variety and emotional colleague support. The reduced model explained $15 \%$ of the variance in occupational expertise. 
The addition of the interaction term resulted in the explained variance of $22 \%$. Given the significant interaction term we conducted extra sums of squares test again. This test helps determine if the increase in the regression sums of squares is significant with the addition of the predictor (Montgomery et al. 2012). The results of the extra sums of squares test for adding an interaction of task variety and emotional colleague support indicated that the incremental variance explained by the full model (model that includes the interaction term) for expertise was significant $\left(\mathrm{F}_{1,112}=10.812, \mathrm{p}=.0013\right)$. This interaction is a double match of extended kind. This means the relationship between occupational expertise and emotional colleague support is moderated by task variety as visualized in Figure 1 below. The relationship between colleague support and occupational expertise is positive and significant $(\mathrm{t}=3.69, \mathrm{p}<.001)$ only when task variety is low. If task variety is high the slope is negative, however not significant $(\mathrm{t}=-$ $.59, \mathrm{p}=.554)$.

$* * * * * * * * * *$ Insert Figure 1 about here $* * * * * * * * * * * * * * *$

\section{Discussion}

Occupational health research until now has mainly dealt with negative outcomes such as poor health and ill-being (Van den Tooren and De Jonge, 2008; Van der Heijden et al., 2008). Since the association between job demands and resources and active learning and growth has also been hypothesized (Bakker and Demerouti, 2007), it is meaningful to examine the association with continued professional development, occupational expertise and personal flexibility as well (Evers et al., 2016). An essential question for continued professional development at work, occupational expertise and personal flexibility is which factors play a role in stimulating it. In this study, we therefore investigated the relationship among job demands and job resources on the one 
hand and health outcomes, continued professional development at work, occupational expertise and personal flexibility on the other.

We hypothesized job demands are positively associated with emotional exhaustion. Job demands consisted of cognitive (challenging work tasks and task variety) and emotional demands. Only emotional demands significantly predicted emotional exhaustion. Previous research also found a positive significant relationship between emotional demands and emotional exhaustion (Xanthopoulou et al., 2007a; Xanthopoulou et al., 2007b; Van den Tooren and De Jonge, 2008). Similarly, to our study, earlier research could not find a relationship between cognitive demands and emotional exhaustion (Van den Tooren and De Jonge, 2008), which is also less likely to occur in the context of the matching theory.

For hypothesis $2 \mathrm{a}$, Job resources are negatively related to emotional exhaustion, we found partial support. Autonomy was significantly and negatively related to emotional exhaustion. Similarly, previous research found a negative correlation between autonomy and emotional exhaustion (Xanthopoulou et al., 2007a). Comparable to our research, earlier research could also not find a relationship between emotional resources and emotional exhaustion (Van den Tooren and De Jonge, 2008).

Hypothesis 2b, job resources are positively associated with teachers' professional development at work, was partly confirmed. Multivariate tests showed a positive significant relationship between emotional supervisor support and emotional colleague support and teachers' professional development at work. This is in line with previous research, which found a positive relationship between social supervisor support and social support from colleagues and teachers' professional development at work in primary and secondary education (Evers et al., 2016). Autonomy was not 
related to any of the six dimensions of teachers' professional development at work, which is in line with Evers et al. (2016).

Hypothesis 2c, job resources are positively associated with occupational expertise, was also partly confirmed. Both autonomy and emotional colleague support were significantly and positively related to occupational expertise. Previous research also found the relationship between these kinds of job resources and motivational aspects like task enjoyment (Bakker et al., 2010). Our research showed that these kinds of job resources are also important in terms of expertise development. Emotional supervisor support was not related to occupational expertise. Earlier research did find a correlation between these two (Evers, 2012), although social support was defined as general social support (consisting of emotional, instrumental, appraisal and informational support, see House, 1981), and not emotional, which could explain the difference. We could not find any support for hypothesis $2 \mathrm{~d}$ : job resources are positively associated with personal flexibility. Previous research was inconclusive about whether job resources were related to personal flexibility. A correlation between social support of the supervisor and personal flexibility was found; but the correlation between social support from colleagues and personal flexibility was non-significant (Evers, 2012). On the other hand, work autonomy was found to be an essential condition in the telecommunications industry for employees' ability to use time flexibly (Rose, 2014). Probably, it is a step too far for job autonomy, as was defined in our study, to influence personal flexibility. Alternatively, this relationship may be domain-specific.

We did not find support for hypothesis 3 - the double match of common kind. Previous research did not find this match for learning and emotional exhaustion as the dependent variables (Van den Tooren and De Jonge, 2008). Hypothesis 4 representing the double match of extended kind: Demand and resource type (emotional or cognitive) 
do not match, but demand or resource type match the outcome type, was partly

supported. We found one double match of extended kind between task variety (a cognitive demand) and emotional colleague support, with occupational expertise (a cognitive outcome) being the dependent variable. If task variety is low, emotional colleague support is significantly and positively related to occupational expertise. In other words, in situations where a teacher has a limited different number of tasks to focus on, colleague support may be used for expertise development. However, if task variety is high, emotional colleague support is not related to occupational expertise. In that case, emotional colleague support is used to cope with the task demands rather than to develop occupation expertise. This mechanism is different than prior theory and research suggest, which is that job resources directly predict motivation and learning, while job demands are positive moderators of this relationship (Bakker et al., 2010). However, in deriving this mechanism they refer to a study of Bakker et al. (2007) in which the dependent variable is work engagement and not learning or motivation. Therefore, the mechanism can be different for learning. Specific job demands and resources may work differently than general demands and resources as explained earlier. Indeed, in our study, this is the case, which may explain the difference in our result compared to previous research and theory.

Hypothesis 5 represented the triple match: Demand types match resource types (emotional or cognitive) and outcome types. This hypothesis was not be supported, which is in line with previous research with regard to learning and emotional exhaustion as the dependent variables (Van den Tooren and De Jonge, 2008).

\section{Implications for Theory}

The findings from this study enable us to better understand the factors that are related to health outcomes, continued professional development at work, occupational expertise 
and personal flexibility of teachers. For instance, we found that emotional support from colleagues and supervisors facilitated professional learning, and that autonomy may be beneficial to reduce emotional exhaustion. The most salient insight from this study, however, is that emotional colleague support may only be used for increasing expertise if task variety (a cognitive demand) is low. If it is too high teachers might simply use the support to manage their tasks or blow off steam. This suggests things may not be as simple as the expectation that learning is stimulated when "arousal", caused by job demands, is changed into a direct (learning) action by application of job resources. Some interactions may indicate more complex mechanisms in play.

Furthermore, little support was found for the matching hypotheses and the DISC-model (De Jonge et al., 2008). This suggests that matching demands and resources do not offer more explanatory power for occupation outcomes than other types of interaction effects. Accordingly, the findings of the present study call into question the notion that job demands are ideally compensated by similar resources. However, it should be noted that some moderating terms pointed in the direction of matching relationships, although these were not statistically significant. While the DISC-model has already been helpful to distinguish between different types of job demands and resources, more work is still needed to explore how these different types interact in bringing about different types of outcomes.

\section{Limitations and further research}

Refinement of the DISC-model could take place through further research into the finding in this study that emotional colleague support only helps to increase expertise if task variety is low. An experiment could be conducted to test this mechanism. A 2x2 between-subject design could be used such that emotional support and task variety are both manipulated. A task would have to be complex enough to require learning. It 
would be expected that individuals who receive emotional support in the condition which has low variety would develop expertise more than individuals in the condition with high task variety. Additionally, qualitative research in which teachers with high and low task variety are probed for their use of emotional colleague support would be helpful to understand the processes that underlie this mechanism.

Future studies in our area may also want to consider the limitations of the present study. The first limitation is the result of the combined effect of the sample size and the methods of analysis. Specifically, outcome measures like TPD at Work, which contains 6 subscales, 3 additional outcomes and a large number of interaction terms are best analyzed in future research by powerful techniques like structural equation modeling (SEM). However, these techniques require 3-5 responses per estimated parameter. While the sample size in our study is larger than sample sizes used in similar studies (e.g. Van den Tooren and De Jonge, 2008) and is acceptable for regression analysis, it is not sufficiently large for structural equation modeling. In addition to investigating an even larger sample size and to perform the research in other educational settings (like primary, secondary and higher education) and occupations, future studies would benefit from exploring the impact of other job resources, such as learning climate, team style and trust which have been hypothesized to play an important role in teacher learning (Evers et al., 2011a). A second limitation is common method variance (the measures were collected in the self-report format and at the same time), although this problem might in some cases be overstated (Spector, 2006).

\section{Implications for practice}

As we noted in our introduction, a thriving question within the field of further and 
higher education is how we can stimulate teachers' continued professional development and at the same time keep them healthy. The findings of our study have two fundamental implications for practice. First, they suggest that schools in vocational education should provide sufficient job resources, such as autonomy and emotional support, if they intend to stimulate teachers' continued professional development. Emotional support by both colleagues and supervisors is strongly related to teachers' participation in professional development activities at work. Meanwhile, a sense of autonomy and emotional support from colleagues will add to teachers' expertise development. Sufficient autonomy will also decrease the chance of emotional exhaustion.

Secondly, our findings indicate that it is essential for schools in vocational education to put a limit on teacher task variety. If task variety is too high, teachers may not leverage emotional colleague support to retain and develop their expertise, but will simply use it to manage their tasks or to blow off steam. While previous research suggests that task variety may be a source for learning (Bakker et al., 2010), our findings indicate that task variety could also not benefit learning that teachers may experience from the emotional support they get from their colleagues. To stimulate teachers' continued professional development, schools should look for a degree of task variety that triggers learning while giving autonomy and leaving room for teachers to use collegial support for their expertise development. 


\section{References}

Avalos, B. (2011), "Teacher professional development in Teaching and Teacher Education over ten years", Teaching and Teacher Education, Vol. 27 No. 1, pp. $10-20$.

Bakker, A.B. and Demerouti, E. (2007), “The job demands-resources model: State of the art", Journal of managerial psychology, Vol. 22 No. 3, pp. 309-328.

Bakker, A.B., Demerouti, E. and Xanthopoulou, D. (2007), “Job resources boost work engagement, particularly when job demands are high", Journal of Educational Psychology, Vol. 99 No. 2, pp. 274-284. doi:10.1037/0022-0663.99.2.274.

Bakker, A.B., Van Veldhoven, M. and Xanthopoulou, D. (2010), "Beyond the DemandControl model: Thriving on High Job Demands and Resources", Journal of Personnel Psychology, Vol. 9 No. 1, pp. 3-16. doi:10.1027/1866-5888/a000006.

Bernabé, M. and Botia, J.M. (2015), "Resilience as a mediator in emotional social support's relationship with occupational psychology health in firefighters", Journal of Health Psychology. Advance online publication. doi: $10.1177 / 1359105314566258$.

Carson, R.L., Baumgartner, J.J., Matthews, R. and Tsouloupas, C.N. (2010), "Emotional exhaustion, absenteeism, and turnover intentions in childcare teachers: examining the impact of physical activity behaviors.", Journal of health psychology, Vol. 15 No. 6, pp. 905-14. doi:10.1177/1359105309360697.

De Jonge, J., and Dormann, C. (2003), “The DISC Model: Demand-Induced Strain Compensation Mechanisms in Job Stress", in Dollard, M.F., Winefield, H.R., and Winefield, A.H. (Eds), Occupational Stress in the Service Professions, Taylor \& Francis, London, UK, pp. 43-74. 
De Jonge, J., and Dormann, C. (2006), "Stressors, Resources, and Strain at Work: A Longitudinal Test of the Triple-Match Principle", The Journal of Applied Psychology Vol. 91 No. 5, pp. 1359-1374. doi:10.1037/0021-9010.91.5.1359.

De Jonge, J., Dormann, C. and Van den Tooren, M. (2008), “The Demand-Induced Strain Compensation Model: Renewed Theoretical Considerations and Empirical Evidence", in Näswall, K., Hellgren, J. and Sverke, M. (Eds), The Individual in the Changing Working Life, Cambridge University Press, Oxford, UK, pp. 67-87.

De Jonge, J, Peeters, M.C.W. and Le Blanc, P.M. (2006), "Emotionele arbeid en positieve werkuitkomsten: De rol van specifieke hulpbronnen in het werk [Emotional work and positive work outcomes: The role of specific job resources].", Gedrag \& Organisatie, Vol. 19 No. 4, pp. 345-367.

Evers, A. T. (2012), Teachers'Professional Development at Work and Occupational Outcomes: An Organisational and Task Perspective, Unpublished Doctoral Dissertation, Open University of the Netherlands, Heerlen, The Netherlands.

Evers, A.T., Kreijns, K. and Van der Heijden, B.I.J.M. (2016), “The Design and Validation of an Instrument to Measure Teachers' Professional Development at Work", Studies in continuing education, Vol. 38 No. 2, pp. 162-178.

Evers, A.T., Kreijns, K., Van der Heijden, B.I.J.M. and Gerrichhauzen, J.T.G. (2011a), “An Organizational and Task Perspective Model Aimed at Enhancing Teachers' Professional Development and Occupational Expertise”, Human Resource Development Review, Vol. 35 No. 1, pp. 24-44.

Evers, A.T., Van der Heijden, B.I.J.M. and Kreijns, K. (2016), “Organisational and task factors influencing teachers' professional development at work", European Journal of Training and Development, Vol. 40 No. 1, pp. 36-55. 
Evers, A.T., Van der Heijden, B.I.J.M., Kreijns, K. and Gerrichhauzen, J.T.G. (2011b), “Organisational Factors and Teachers' Professional Development in Dutch Secondary Schools", Journal of European Industrial Training, Vol. 35 No. 1, pp. 24-44. doi:10.1108/03090591111095727.

Evers, A.T., Van der Heijden, B.I.J.M., Kreijns, K. and Vermeulen, M. (2016), “Job Demands, Job Resources, and Flexible Competence: The Mediating Role of Teachers' Professional Development at Work", Journal of Career Development, Vol. 43 No. 3, pp. 227-243. doi:10.1177/0894845315597473.

Frese, M. (1999), "Social support as a moderator of the relationship between work stressors and psychological dysfunctioning: a longitudinal study with objective measures", Journal of occupational health psychology, Vol. 4 No. 3, pp. 179192.

Hackman, J.R., and Oldham, G.R. (1980), Work redesign, Addison Wesley, Reading: MA.

Hattie, J. (2008), Visible Learning: A Synthesis of Over 800 Meta-Analyses Relating to Achievement, Routledge, London, UK.

Hockey, G.R.J. (2000), “Work Environments and Performance”, in Chmiel, N. (Ed), Introduction to Work and Organizational Psychology: A European Perspective, Blackwell Publishers, Oxford, UK, pp. 206-230

House, J.S. (1981), Work stress and social support, Addison Wesley, Reading: MA. Johnson, R.A. and Wichern, D.W. (2002), Applied multivariate statistical analysis, Prentice Hall, Upper Saddle River: NJ.

Jones F. and Fletcher, B. (1996), “Job control and health”, in Schabracq, M.J., Winnubst, J.A.M. and Cooper, C. L. (Eds), Handbook of Work and Health Psychology, Wiley, Chichester, pp. 33-50. 
Karasek, R.A., Triantis, K.P. and Chaudry, S.S. (1982), “Coworker and Supervisor support as moderators of associations between task characteristics and mental strain”, Journal of Organizational Behavior, Vol. 3 No. 2, pp. 181-200. doi: 10.1002/job.4030030205.

Kwakman, K. (2001), "Work stress and work-based learning in secondary education: Testing the Karasek model”, Human Resource Development International, Vol. 4, pp. 487-501. doi:10.1080/13678860010004123.

Kwakman, K. (2003), “Factors affecting teachers' participation in professional learning activities", Teaching and teacher education, Vol. 19 No. 2, pp. 149-170. doi:10.1016/S0742-051X(02)00101-4.

Misiołek, A., Gil-Monte, P.R. and Misiołek, H. (2017), "Prevalence of Burnout in Polish Anesthesiologists and Anesthetist Nursing Professionals: A Comparative Non-Randomized Cross-Sectional Study”, Journal of Health Psychology, Vol. 22 No. 4, pp. 465-474. doi:10.1177/1359105315604377.

Montgomery, D.C., Peck, E.A. and Vining, G.G. (2012), Introduction to linear regression analysis, John Wiley \& Sons, Hobokon, New Jersey.

Nie, Y., and Sun, H. (2015), "Why Do Workaholics Experience Depression? A Study with Chinese University Teachers”, Journal of Health Psychology, Vol. 21 No. 10, pp. 1-8. doi:10.1177/1359105315576350.

Olson, C. L. (1979), "Practical considerations in choosing a MANOVA test statistic: A rejoinder to Stevens", Psychological Bulletin, Vol. 86 No. 6, pp. 1350-1352. doi:10.1037/0033-2909.86.6.1350.

Pu, J., Hou, H., Ma, R. and Sang, J. (2016), “The Effect of Psychological Capital between Work-Family Conflict and Job Burnout in Chinese University Teachers: Testing for Mediation and Moderation", Journal of Health 
Psychology, Advance online publication, pp. 1-9.

doi:10.1177/1359105316636950.

Rose, E. (2014), “Temporal Flexibility and its Limits: The Personal Use of ICTs at Work", Sociology, Vol. 49 No. 3, pp. 505-520.

doi:10.1177/0038038514542121.

Spector, P.E. (2006), "Method variance in organizational research: truth or urban legend?", Organizational research methods, Vol. 9, No. 2, pp. 221-232. doi:10.1177/1094428105284955.

Van den Tooren, M. and de Jonge, J. (2008), "Managing job stress in nursing: what kind of resources do we need?", Journal of advanced nursing, Vol. 63 No. 1, pp. 75-84. doi:10.1111/j.1365-2648.2008.04657.x.

Van der Heijde, C.M. and Van der Heijden, B.I.J.M. (2006), “A competence-based and multidimensional operationalization and measurement of employability", Human Resource Management, Vol. 45 No. 3, pp. 449-476. doi:10.1002/hrm.20119.

Van der Heijden, B.I.J.M., Demerouti, E., Bakker, A.B. and Hasselhorn, H. (2008), "Work-home interference among nurses: reciprocal relationships with job demands and health", Journal of Advanced Nursing, Vol. 62 No. 5, pp. 572-584. doi: 10.1111/j.1365-2648.2008.04630.x.

Van Veldhoven, M. and Meijman, T.F. (1994), Het meten van psychosociale arbeidsbelasting met een vragenlijst (VBBA): [The measurement of psychosocial work demands with a questionnaire (VBBA)], Dutch Institute of Working Conditions, Amsterdam. 
Webb, S. and Napier, J. (2015). "Job Demands and Resources: An exploration of sign language interpreter educators' experiences", International Journal of Interpreter Education, Vol. 7 No. 1, pp. 23-50.

Xanthopoulou, D., Bakker, A.B., Demerouti, E. and Schaufeli, W.B. (2007a), "The role of personal resources in the job demands-resources model", International Journal of Stress Management, Vol. 14 No. 2, pp. 121-141. doi:10.1037/10725245.14.2.121.

Xanthopoulou, D., Bakker, A.B., Dollard, M.F., Demerouti, E., Schaufeli, W.B., Taris, T.W. and Schreurs, P.J.G. (2007), “When do job demands particularly predict burnout?: The moderating role of job resources", Journal of Managerial Psychology, Vol. 22 No. 8, pp. 766-786. doi:10.1108/02683940710837714. 
Table 1. Descriptive statistics, reliabilities, and correlations among study variables (Cronbach's alpha italicized on the Diagonal).

\begin{tabular}{|c|c|c|c|c|c|c|c|c|c|c|c|c|c|c|c|c|c|c|c|c|}
\hline & Mean & SD & Reading & Training & Experimenting & Reflection & $\begin{array}{l}\text { Collobarating on } \\
\text { Lessons }\end{array}$ & $\begin{array}{l}\text { Collobarting on } \\
\text { School }\end{array}$ & Expertise & Flexibility & $\begin{array}{l}\text { Emotional } \\
\text { Exhaustion }\end{array}$ & Autonomy & Task Variety & $\begin{array}{l}\text { Cognitive } \\
\text { Demands }\end{array}$ & $\begin{array}{l}\text { Emotional } \\
\text { Demands }\end{array}$ & $\begin{array}{l}\text { Supervisor } \\
\text { Support }\end{array}$ & $\begin{array}{l}\text { Colleague } \\
\text { Support } \\
\end{array}$ & Gender & Experience & Education Level \\
\hline Reading & 2.69 & 0.8 & .79 & & & & & & & & & & & & & & & & & \\
\hline Training & 2.23 & 0.72 & $0.52^{* * *}$ & .75 & & & & & & & & & & & & & & & & \\
\hline Experimenting & 2.38 & 0.7 & $0.44^{* * *}$ & $0.38^{* * *}$ & .87 & & & & & & & & & & & & & & & \\
\hline Reflection & 2.58 & 0.6 & $0.27^{* *}$ & $0.24^{* *}$ & $0.57^{* * *}$ & .71 & & & & & & & & & & & & & & \\
\hline Collobarating on Lessons & 2.41 & 0.68 & $0.19 *$ & $0.34^{* * *}$ & $0.44^{* * *}$ & $0.59 * *$ & .72 & & & & & & & & & & & & & \\
\hline Collobarting on School & 2.57 & 0.64 & $0.23^{*}$ & $0 . .^{* * *}$ & $0.27^{* *}$ & $0.5 * * *$ & $0.59^{* * *}$ & .73 & & & & & & & & & & & & \\
\hline Expertise & 4.53 & 0.46 & 0.12 & 0.09 & 0.24 & 0.42 & 0.32 & 0.32 & .85 & & & & & & & & & & & \\
\hline Flexibility & 4.51 & 0.49 & 0.07 & 0.09 & 0.17 & 0.32 & 0.29 & 0.33 & $0.72^{* * *}$ & .79 & & & & & & & & & & \\
\hline Emotional Exhaustion & 1.98 & 0.68 & -0.08 & -0.04 & -0.05 & -0.16 & -0.04 & -0.07 & $-0.36^{* * *}$ & $-0.39 * * *$ & .85 & & & & & & & & & \\
\hline Autonomy & 2.48 & 0.6 & 0.08 & -0.01 & 0.05 & 0.15 & 0.12 & 0.18 & $0.31^{* * *}$ & $0.28^{* *}$ & $-0.31^{* * *}$ & .84 & & & & & & & & \\
\hline Task Variety & 3.12 & 0.53 & 0.08 & 0.09 & 0.1 & $0.25^{* *}$ & $0.2^{*}$ & $0.24^{* *}$ & $0.1^{*}$ & $0.12^{*}$ & -0.1 & $0.26^{* *}$ & .78 & & & & & & & \\
\hline Cognitive Demands & 2.64 & 0.48 & 0.09 & 0.02 & 0.15 & 0.19 & $0.21^{*}$ & $0.21^{*}$ & -0.05 & 0.05 & $0.37^{* * *}$ & 0.09 & $0.34^{* * *}$ & .67 & & & & & & \\
\hline Emotional Demands & 2.13 & 0.52 & -0.05 & 0.05 & 0.03 & -0.09 & -0.08 & -0.01 & $-0.31^{* * *}$ & $-0.34^{* * *}$ & $0.59 * * *$ & $-0.23^{*}$ & -0.01 & $0.49 * * *$ & .72 & & & & & \\
\hline Supervisor Support & 2.92 & 0.87 & $0.32^{* * *}$ & $0.23^{*}$ & $0.23^{*}$ & $0.3^{* * *}$ & $0.26^{* *}$ & $0.31^{* * *}$ & $0.23^{* *}$ & $0.27 * *$ & -0.05 & $0.37^{* * *}$ & $0.32^{* * *}$ & 0.14 & -0.13 & .95 & & & & \\
\hline Colleague Support & 3.29 & 0.65 & 0.06 & 0.13 & -0.06 & $0.2^{*}$ & $0.28^{* *}$ & $0.32^{* * *}$ & $0.23^{* *}$ & 0.15 & $-0.18^{*}$ & 0.15 & 0.12 & -0.15 & -0.13 & $0.24^{* *}$ & .92 & & & \\
\hline Gender & - & - & 0.05 & 0.2 & 0.00 & 0.1 & 0.13 & 0.08 & 0.05 & 0.02 & -0.04 & 0.13 & $0.24^{* *}$ & 0.01 & -0.03 & $0.19^{*}$ & 0.2 & - & & \\
\hline Experience & 18.61 & 10.17 & 0.08 & $0.22^{*}$ & 0.03 & -0.16 & -0.11 & 0.00 & -0.11 & -0.05 & 0.16 & -0.08 & 0.00 & 0.09 & 0.13 & -0.06 & -0.17 & 0.13 & -- & \\
\hline Education Level & 1.97 & 0.46 & -0.08 & -0.13 & -0.08 & -0.14 & -0.02 & -0.12 & -0.12 & -0.04 & -0.1 & -0.15 & -0.12 & -0.05 & -0.07 & -0.07 & -0.06 & -0.18 & -0.11 & -- \\
\hline
\end{tabular}

Croncbach's Alphas on main diagonal 
Table 2. Hierarchical regression results for double matches of extended and common kind for Job Demands, Job Resources and Job Outcomes (emotional exhaustion, expertise, and flexibility).

\begin{tabular}{|c|c|c|c|c|c|c|}
\hline & \multicolumn{2}{|c|}{ Emotional Exhaustion } & \multicolumn{2}{|c|}{ Expertise } & \multicolumn{2}{|c|}{ Flexibility } \\
\hline & B & St. E. & B & St. E & B & St. E. \\
\hline \multicolumn{7}{|l|}{ Demands and Resources } \\
\hline Autonomy & $-0.24 *$ & 0.09 & $0.17^{*}$ & 0.07 & 0.11 & 0.08 \\
\hline Emotional Colleague Support & -0.07 & 0.08 & $0.16^{*}$ & 0.06 & 0.07 & 0.07 \\
\hline Emotional Supervisor Support & 0.09 & 0.06 & 0.03 & 0.05 & 0.08 & 0.06 \\
\hline Task Variety & -0.14 & 0.10 & -0.05 & 0.08 & -0.05 & 0.09 \\
\hline Cognitive Demands & 0.22 & 0.13 & 0.15 & 0.11 & $0.28^{*}$ & 0.12 \\
\hline Emotional Demands & $0.61^{* * *}$ & 0.12 & $-0.29 * *$ & 0.09 & $-0.40 * * *$ & 0.10 \\
\hline \multicolumn{7}{|l|}{ Moderating Terms } \\
\hline Autonomy x Task Variety & $-0.23 \mathrm{DMc}$ & 0.16 & $-0.15 T M$ & 0.13 & $0.10 \mathrm{TM}$ & 0.14 \\
\hline Emotional Colleague Support x Task Variety & -0.21 & 0.17 & $-0.41^{* *}$ & 0.14 & -0.26 & 0.15 \\
\hline Emotional Supervior Support x Task Variety & 0.18 & 0.13 & 0.12 & 0.10 & 0.06 & 0.11 \\
\hline Autonomy $\times$ Cognitive Demands & $0.31 \mathrm{DMc}$ & 0.22 & -0.12 & 0.18 & -0.10 & 0.20 \\
\hline $\begin{array}{l}\text { Emotional Colleague Support x Cognitiv } \\
\text { Demands }\end{array}$ & -0.14 & 0.22 & -0.06 & 0.18 & 0.15 & 0.20 \\
\hline $\begin{array}{l}\text { Emotional Supervior Support x Cognitive } \\
\text { Demands }\end{array}$ & -0.14 & 0.15 & 0.16 & 0.12 & 0.04 & 0.13 \\
\hline Autonomy x Emotional Demands & -0.33 & 0.19 & 0.06 & 0.15 & -0.05 & 0.17 \\
\hline $\begin{array}{l}\text { Emotional Colleague Support x Emotional } \\
\text { Demands }\end{array}$ & $-0.09 \mathrm{TM}$ & 0.18 & $-0.10 \mathrm{DMc}$ & 0.14 & $-0.07 \mathrm{DMc}$ & 0.15 \\
\hline $\begin{array}{l}\text { Emotional Supervior Support x Emotional } \\
\text { Demands }\end{array}$ & $-0.08 \mathrm{TM}$ & 0.14 & $-0.17 \mathrm{DMc}$ & 0.11 & $-0.05 \mathrm{DMc}$ & 0.13 \\
\hline & \multicolumn{2}{|l|}{$R=.51$} & \multicolumn{2}{|l|}{$\mathrm{R}=.32$} & \multicolumn{2}{|l|}{$R=.27$} \\
\hline & \multicolumn{2}{|c|}{$F(15,104)=7.215, * * *$} & \multicolumn{2}{|c|}{$F(15,104)=3.224^{* * *}$} & \multicolumn{2}{|c|}{$F(15,104)=2.548^{* *}$} \\
\hline & \multicolumn{2}{|c|}{ Adjusted $R=.44$} & \multicolumn{2}{|c|}{ Adjusted $\mathrm{R}=.22$} & \multicolumn{2}{|c|}{ Adjusted $R=.16$} \\
\hline
\end{tabular}


Figure 1. Double match of extended kind: task variety moderates the relationship between emotional colleague support and occupational expertise

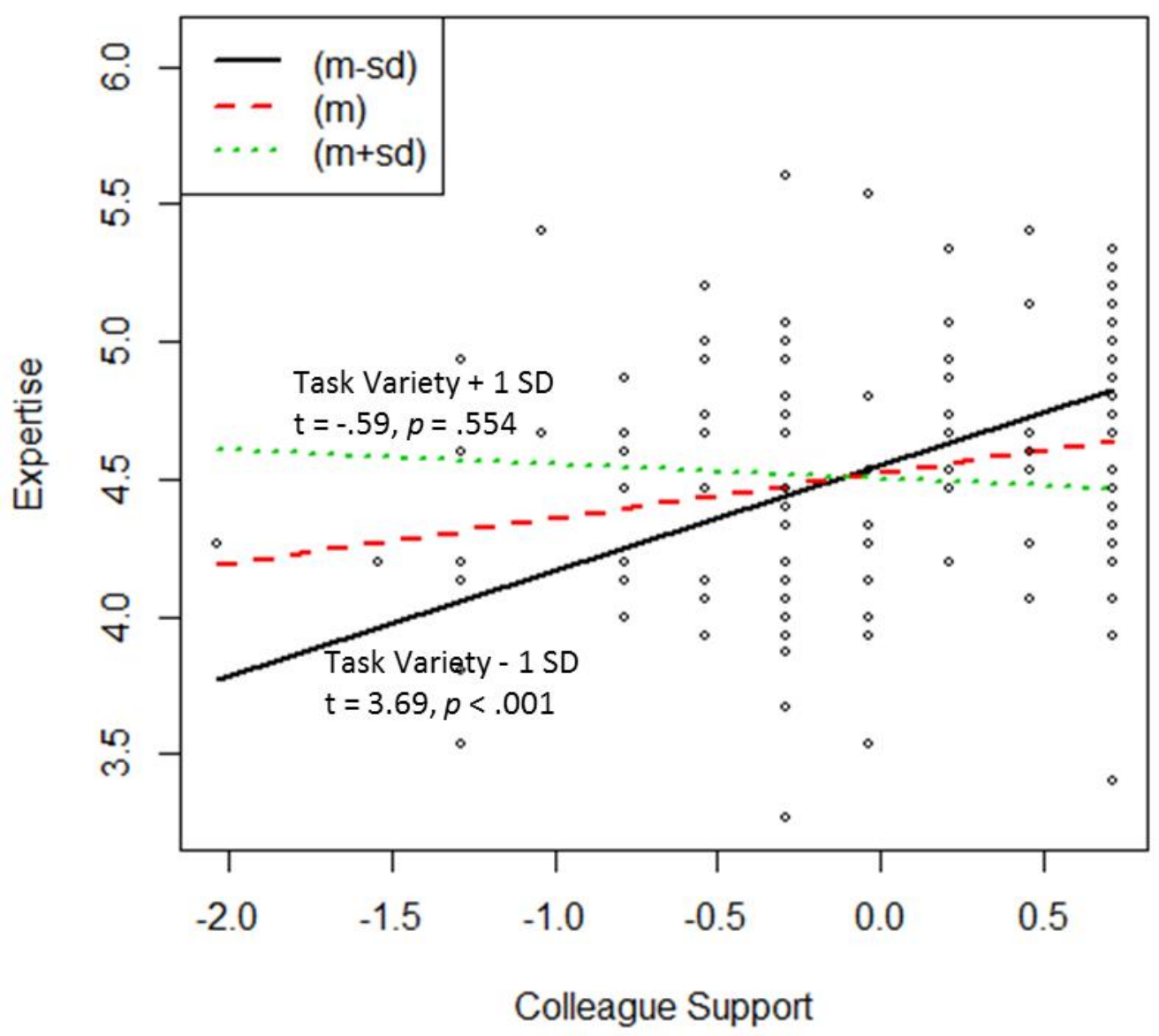

